\title{
Chest wall "pneumoma": a hitherto unreported clinical entity
}

\author{
BANERJEE, SK KHANNA, PS NARAYANAN \\ From the Department of Cardiothoracic Surgery, GB Pant Hospital, New Delhi, India
}

We report the first case in which a localised, well-defined, chest wall swelling has been found to contain only a subcutaneous collection of air. The patient has been investigated and satisfactorily treated. We propose that this new clinical entity should be called a "pneumoma."

\section{Case report}

The patient (RC), a man aged 21 years, was admitted to the GB Pant Hospital, New Delhi, complaining of a swelling over the left back, which had grown steadily over four months. The swelling, initially asymptomatic, had become progressively painful and tender to touch. Direct questioning disclosed a neglected injury caused by a blunt object in the same area about a month before the appearance of the swelling. A history of any congenital abnormality or respiratory or bowel disorder was denied.

Address for reprint requests: Dr Banerjee, 249 Sheikh Sarai, New Delhi-110017, India.

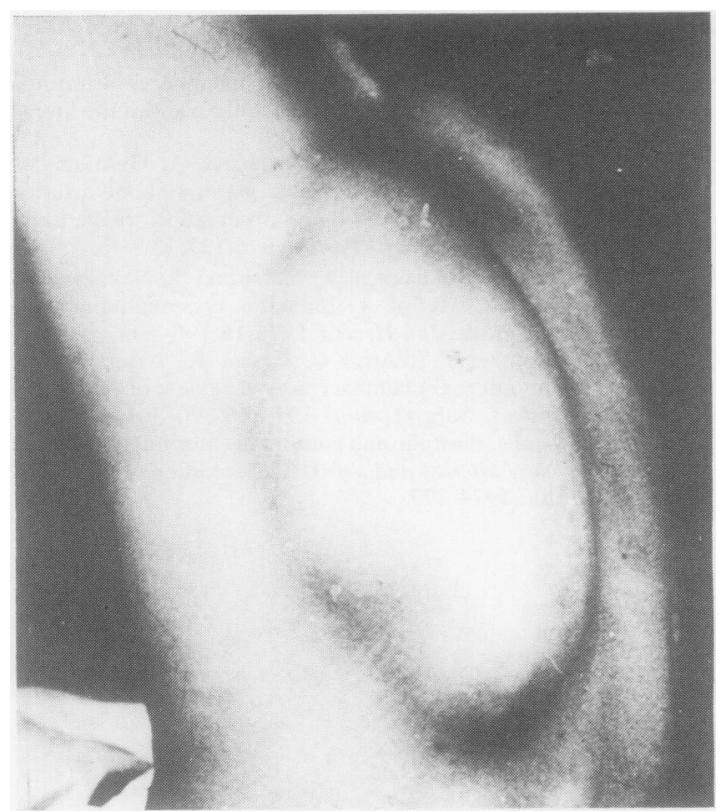

Fig 1 Clinical photograph showing the swelling lying to the left of the spine.
General physical and systemic examination was normal. The swelling, $30 \times 15 \mathrm{~cm}$, was oval in shape and (fig 1) occupied the left paraspinal region, overlying the lower thoracic and upper lumbar areas. It had a fairly welldefined margin merging smoothly with the surroundings. It was soft, cystic, tender, and fluctuant in both axes. The brilliantly transilluminant swelling was resonant on percussion with no obvious features of inflammation. Crepitus, cough impulse, and succussion splash were absent. There was no deformity of the thoracic cage or the spine.

Routine blood and urine examinations were normal. The chest and dorsolumbar spine appeared radiographically normal. Oblique and lateral skiagrams centred upon the swelling showed a soft tissue shadow enclosing a loculated collection of air (fig 2). The possibility of an enterogenous origin of the lesion was ruled out by demonstrating a normal gastrointestinal tract on barium examination.

Complete emptying, by aspiration of air (no fluid could be drawn), led to collapse of the swelling, only for it to be filled up again with air within three or four days. Bronchography showed a normal bronchial structure and failed to show any obvious broncho-pleuro-subcutaneous fistula. Injection of radio-opaque material into the swelling revealed no communication with any air-containing viscus. The aspirated air was sterile on culture. An attempt to stimulate the formation of adhesions and obliteration of the space by insertion of an antigravity drainage catheter, connected to a continuous low-pressure suction system for three weeks, succeeded in temporarily emptying the cavity but failed to obliterate it.

Surgical exploration of the cyst revealed a smooth and uniform cyst wall lining in the subcutaneous plane, with intermittent bands of fibrous tissue. There was no overt evidence of air leak at any point under positive-pressure ventilation on the operating table. A closer examination showed an area over the posterior aspect of the ninth rib which looked like a focus of granulation tissue overlying a healed fracture. The epithelialised wall of the cavity was excised completely and the granulomatous area was thoroughly diathermised and underrun with fine sutures. The overlying skin was suitably trimmed and closed leaving a drainage tube for 48 hours. The wound healed by primary intention with no recurrence of the condition during one year. Histopathological examination of the cyst wall showed non-specific inflammatory tissue.

\section{Discussion}

Abnormal air in the tissues usually manifests itself as emphysema, which spreads throughout the muscle and 


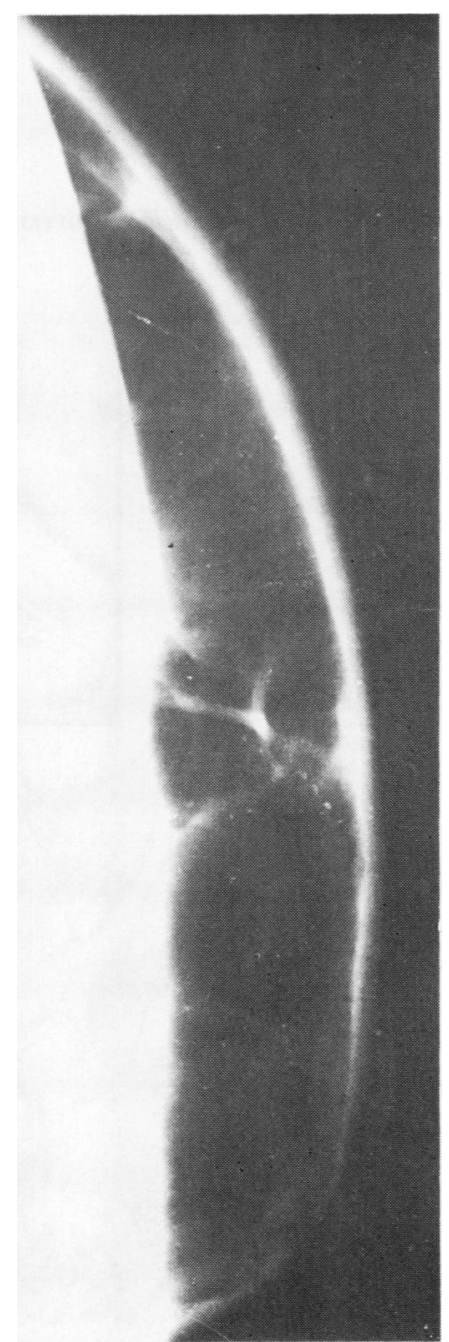

connective tissue planes. Such air may result from an injury to any of the air-containing viscera, a valve-like injury to the skin, or infection with air-producing organisms. In all such cases, however, the extravasated air, which dissects through the tissue planes, is absorbed within a few days. We could not find any documented evidence of a localised subcutaneous collection of air which filled up within a few days of complete evacuation, as in this case.

The pathogenesis of this case is not clearly understood. Possibly the blunt trauma suffered before the appearance of the swelling produced a fracture of the ninth rib, with a broncho-pleuro-subcutaneous fistula which was restricted by a haematoma. The haematoma could then have been absorbed giving rise to a loculated air collection which progressively increased in amount, causing the cyst, though the mechanism by which the space became epithelialised remains an enigma. A valve-like action produced by an oblique, narrow fistula could have prevented its demonstration from within or from without and yet permitted a steady leak of air, allowing the emptied cavity to refill within a few days. Excision of the cavity wall accompanied by coagulation and suturing of the suspicious area apparently successfully closed the fistula. Our inability to demonstrate the escape of air at the time of surgery remains unexplained.

Fig 2 Lateral radiograph centring on the swelling showing the loculated subcutaneous collection of air. 


\section{Correspondence}

\section{Toxicity of high-dose intrapleural BCG}

SIR,-W Bakker and his colleagues (November 1981, p 870 ) have reported on the enhancement of tumour growth after the intrapleural administration of BCG to stage I lung cancer patients. In a related article this same group has described other toxic complications after intrapleural BCG.'

The likelihood that the complications associated with intrapleural BCG were due to the unconventionally high dose of BCG they used is not adequately stressed by the authors. Fifty-eight of the sixty-four patients treated with intrapleural BCG in this study received three to six times the dose used in other studies of intrapleural BCG for lung cancer. $^{2-4}$ BCG was not associated with serious complications or enhancement of tumour growth in any of these studies. Jansen et $\mathrm{ll}^{5}$ have also encountered complications in nine out of 14 patients given an intrapleural dose of BCG $\left(35 \times 10^{6}\right.$ viable units). This dose was similar to that used in the study by Dr Bakker and others $\left(32 \times 10^{6}\right.$ viable units). If the title of this publication had been "Postoperative high-dose intrapleural BCG in lung cancer: lack of efficacy and possible enhancement of tumour growth" it would have more accurately reflected the outstanding feature of this study.

JA BENNETT

MF MCKNEALLY

Division of Cardiothoracic Surgery

Albany Medical College

Albany, NY 12208, USA

\section{References}

' Bakker W, Nijhuis-Heddes JMA, Brutel de la Riviere A, Dijkman JH. Ann Thorac Surg 1982;33:267-72.

${ }^{2}$ McKneally MF, Maver C, Lininger L, et al. J Thorac Cardiovasc Surg 1981;81:485-92.

${ }^{3}$ Lowe J, Shore DF, Iles PB, Langman MJS, Baldwin RW. Lancet $1980 ;$ i: $11-4$.

4 North American Lung Cancer Study Group. Cancer Immunol Immunother 1981;10:129-37.

5Jansen HM, The TH, Orie NGM, et al. Thorax 1980;35:781-7.

SIR-Different BCG vaccine products show different biological characteristics depending on the method of preparation. This aspect of adjuvant therapy hinders proper comparison of studies with different BCG strains and preparations as we stressed in the article to which Drs Bennett and McKneally refer. As we used a modified Pasteur strain we could not rely on the dose recommended by those who used a Tice strain ${ }^{1}$ or a Glaxo strain (reference 3 above). We had to perform preliminary experiments in animals to determine the dosage of our Pasteur strain, as $\mathrm{Dr}$ McKneally and his colleagues did with his Tice strain. ${ }^{1}$ However, the Ludwig Lung Cancer Study Group modelled its BCG treatment as closely as possible on the therapy of McKneally, using the same strain and dose. This group found, in a randomised clinical trial, ${ }^{2}$ complications similar to those we found. Its current data suggest that BCG is associated with a shorter disease-free interval than is placebo (paper presented to Third World Conference on Lung Cancer, 1981). Therefore the dose of BCG alone clearly cannot be held responsible for the discrepancy between our results and those of McKneally.

W BAKKER

JMA NIJHUIS-HEDDES

A BRUTEL DE LA RIVIERE

AMJ WEVER

EA van der VELDE

JH DIJKMAN

Department of Pulmonology

University Hospital

2333 AA Leiden

Holland

\section{References}

' McKneally MF, Maver C, Kansel HW, Alley RD. J Thorac Cardiovasc Surg 1976;72:333-8.

${ }^{2}$ Ludwig Lung Cancer Study Group. N. Engl J Med 1981;305: 167-8.

\section{Notice}

\section{International workshop and meeting on receptors and chronic obstructive lung disease}

An international workshop on receptors and chronic obstructive lung disease is to be held by the Netherlands Asthma Foundation in Utrecht on 4 November 1982 for not more than 150 investigators. It will be followed on 5 November by an international meeting on the same subject in which the emphasis will be on the implications for clinical practice. This will welcome in particular chest physicians; paediatricians; immunologists; ear, nose, and throat surgeons; and pharmacologists. Applications for registering for both meetings and for giving short communications and poster sessions at the workshop should be made to the Secretariat, Nederlands Astma Fonds, Postbus 5, 3830AA Leusden, The Netherlands.

\section{Correction}

\section{Chest wall "pneumoma": a hitherto unreported clinical entity}

We greatly regret that in the report by Amit Banerjee and others (May 1982, p 388) Dr Banerjee's first name was omitted. 